\title{
Prenatal diagnosis for haemophilia: a nationwide survey among female carriers in the Netherlands
}

\author{
D. M. W. BALAK, * S. C. GOUW, *†I. PLUG, \$E. P. MAUSER-BUNSCHOTEN, $\mathbb{S}$ A. H. J. T. VRIENDS, \\ J. E. M. VAN DIEMEN-HOMAN, F. R. ROSENDAAL* and J. G. VAN DER BOM*** \\ *Department of Clinical Epidemiology, Leiden University Medical Center, Leiden; $\dagger$ Department of Pediatrics, Wilhelmina \\ Children’s Hospital, Utrecht; $\$$ Department of Public Health, Erasmus University Medical Center, Rotterdam; $\$$ Van \\ Creveldkliniek and Department of Hematology, University Medical Center Utrecht, Utrecht; $\uparrow$ Center for Human and Clinical \\ Genetics, Leiden University Medical Center, Leiden; and *Sanquin-LUMC Jon J van Rood Center for Clinical Transfusion \\ Research, Sanquin Foundation, Leiden, The Netherlands
}

\begin{abstract}
Summary. Carriers of haemophilia face difficult choices regarding prenatal diagnosis, but little is known about the determinants that influence their decisions. The aim of this study was to assess the incidence of prenatal diagnosis and potential determinants affecting the choice for prenatal diagnosis. A nationwide survey was performed among all women who underwent carriership testing for haemophilia in the Netherlands between 1992 and 2004. Prenatal diagnosis was assessed in 207 carriers of haemophilia A or B who had been pregnant. Prenatal diagnosis was categorized into early first trimester (Y-PCR testing or chorionic villus sampling) often intended to prevent the birth of a child with haemophilia, and into late prenatal diagnosis (amniocentesis or ultrasound assessment) aimed at obstetrical management. Of 207 carriers $112(54 \%)$ underwent prenatal diagnosis. Forty-eight women underwent early prenatal diagnosis and 64 women underwent late prenatal diagnosis. In
\end{abstract}

26 pregnancies early prenatal diagnosis was positive for haemophilia, and in 18 of these pregnancies termination was opted for. The choice for early prenatal diagnosis was associated with a liberal view towards termination of pregnancy (relative risk (RR) 12.5; 95\% confidence interval (CI) 3.1-51.2), severe haemophilia in the family (RR 20.2; CI 2.7-153.6), absence of a religion (RR 1.9; CI 1.1-3.1) and older age (RR 2.0; CI 1.0-3.9). The choice for late prenatal diagnosis was associated with birth year after 1970 (RR 2.3; CI 1.5-3.5) and a previous child with haemophilia (RR 2.2; CI 1.4-3.4). More than half of all Dutch haemophilia carriers underwent prenatal diagnosis. Several determinants were strongly associated with prenatal diagnosis.

Keywords: amniocentesis, carriers, chorionic villus biopsy, foetal gender determination, reproductive choices, termination of pregnancy

\section{Introduction}

Haemophilia is an X-linked recessive inherited bleeding disorder that arises from reduced levels of functional coagulation factor VIII (haemophilia A) or factor IX (haemophilia B). Both types of haemophilia are rare diseases, with prevalence of 1 in 5000 male live births for haemophilia A and 1 in 30000 for haemophilia B [1]. The residual plasma concentration of the coagulation factor determines the bleeding phenotype and

Correspondence: Johanna G. van der Bom, MD, PhD, Department of Clinical Epidemiology, Leiden University Medical Center, PO Box 9600, 2300 RC Leiden, The Netherlands.

Tel.: +31 71526 1562; fax: +31 71526 6994;

e-mail: j.g.van_der_bom@lumc.nl

Accepted after revision 13 December 2011 severe haemophilia is characterized by spontaneous haemorrhages into muscles and joints, leading to significant morbidity [2]. In spite of the advances made in the management for haemophilia, a definite cure is still lacking so that haemophilia remains a chronic and incurable condition $[3,4]$.

Prenatal diagnosis for haemophilia plays a pivotal role in the genetic counselling for couples who are at risk of having an affected child. Prenatal diagnosis may be offered for two reasons: either to prevent the birth of a child with haemophilia by early termination of an affected pregnancy or to determine the need for specific obstetrical precautions $[5,6]$.

Couples at risk considering prevention of the birth of a child with haemophilia are offered early invasive prenatal diagnosis. DNA analysis on foetal cells obtained by chorionic villus sampling or by 
amniocentesis has been available from the mid-1980s onwards. Both methods are associated with a $0.5-1.0 \%$ risk of procedure-related miscarriage [7]. Chorionic villus sampling can be performed at 11-14 weeks of gestation and therefore allows a diagnosis of an affected pregnancy in the first trimester. Amniocentesis, however, can only be performed in the 16-17th week of gestation. Chorionic villus sampling is therefore preferred over amniocentesis when termination of an affected pregnancy is considered [8,9]. More recently, the determination of the foetal gender in the 7-11th weeks of pregnancy became available by analysis of free foetal DNA isolated from maternal blood [8,10-12]. Using this so-called Y-PCR testing in female foetuses, invasive procedures and associated risks can be avoided. Another method for prenatal diagnosis is the direct measurement of clotting factor activity in foetal blood by cordocentesis (i.e. percutaneous umbilical cord blood sampling). However, its use in the last two decades has been limited to rare situations in which other techniques are not available or in which other techniques yielded inconclusive results [9].

Couples at risk who do not wish to prevent the birth of an affected child are offered foetal gender determination later in the pregnancy. In case of a male foetus, the use of invasive foetal monitoring during the delivery and instrumental delivery is restricted to diminish the foetal bleeding risk. Ultrasound assessment allows reliable foetal gender determination in the second trimester [9]. This may be followed by a late amniocentesis in the third trimester to determine the haemophilia status of a male foetus [6].

Carriers of haemophilia face difficult choices regarding reproduction and prenatal diagnosis, and these complex decisions are likely to be influenced by psychological, cultural and ethical factors [13-16]. Relatively little is known about carriers' attitudes and other determinants that influence prenatal diagnosis for haemophilia. More knowledge on these issues may improve quality of counselling, and may allow better informed reproductive and obstetric choices for couples at increased risk for having a child with haemophilia.

In the present nationwide cross-sectional study, our aim was to assess how many carriers of haemophilia in the Netherlands had undergone prenatal diagnosis, to summarize the used methods and outcomes of prenatal diagnosis, and to evaluate potential determinants affecting the choice for prenatal diagnosis.

\section{Material and methods}

\section{Study population}

This study is based on data from a nationwide postal survey conducted in 2004 among all women who underwent carrier testing for haemophilia A or B in the Netherlands during the period 1992-2004 [17]. The survey was part of the Haemophilia in the Netherlands5 (HiN-5) study, which was designed to study attitudes and consequences concerning haemophilia, haemophilia carriership and haemophilia treatment.

Women aged 18 years or older participated in this survey. The questionnaire was sent to all 766 women who underwent carriership testing for haemophilia A or B in the Netherlands between 1992 and 2004. Carriership for haemophilia was assessed at either of two centres, the Department of Clinical Genetics of the Leiden University Medical Center or at the Van Creveldkliniek and Department of Clinical Genetics of the University Medical Center Utrecht. Of these 766 women, 546 (71\%) responded and completed the questionnaire. Carriers of haemophilia who had been pregnant at least once after carrier testing, and thus had faced the choice for prenatal diagnosis for haemophilia in at least one pregnancy were eligible for this study. We therefore excluded women who were non-carriers $(n=245)$, women with an unknown or inconclusive carrier status $(n=10)$, women with clotting disorders other than haemophilia $(n=19)$, women who had never been pregnant $(n=43)$ and carriers with a son with isolated haemophilia who did not become pregnant again after carrier testing $(n=22)$. This left 207 women for the present analyses.

\section{Data collection}

The questionnaire collected data on demographic characteristics, number of pregnancies and children, religion, type and perceived severity of haemophilia in the family and methods and outcomes of prenatal diagnosis. In addition, bleeding tendency was recorded using a validated questionnaire on a variety of bleeding symptoms [18]. The carrier status, clotting factor level and type and severity of haemophilia in the family were verified at the haemophilia treatment centres.

The study was approved by the Committee of Medical Ethics of the Leiden University Medical Center. All participants gave informed consent.

\section{Definitions}

Carriers of haemophilia were women in whom a gene mutation causing haemophilia A or B was shown by DNA analysis or in whom linkage analysis showed carriership, women who were obligate carriers based on pedigree analysis, and women for whom a high probability of carriership was calculated based on pedigree analysis and clotting factor levels. Non-carriers were women in whom testing (DNA analysis, pedigree analysis and clotting factor levels) showed that they did not carry the causative mutation or the related haplotype. 
Prenatal diagnosis was defined as any form of testing for haemophilia or for foetal gender during pregnancy. Prenatal diagnosis was categorized into first trimester early prenatal diagnosis (i.e. chorionic villus sampling and Y-PCR testing) and prenatal diagnosis performed later in pregnancy (i.e. ultrasound assessment and amniocentesis). This classification was chosen, because only women considering termination of an affected pregnancy were offered early prenatal diagnosis by chorionic villus sampling, which in later years was preceded by Y-PCR testing. In contrast, late prenatal diagnosis by ultrasound assessment and third trimester amniocentesis was offered to determine the need for specific obstetric precautions. The only exception to this is second trimester amniocentesis, which may be performed in view of terminating an affected pregnancy rather than to determine the management during delivery. However, in our dataset the distinction between second and third trimester amniocentesis was not possible.

Severity of bleeding tendency of carriers was graded with a bleeding score ranging from 0 to 4; the higher the bleeding score, the higher the bleeding tendency $[17,18]$. The disease severity of haemophilia in the family was categorized according to the residual plasma activities of factor VIII or IX in index patients: severe $\left(<0.01 \mathrm{IU} \mathrm{mL}^{-1}\right)$, moderate $\left(0.01-0.05 \mathrm{IU} \mathrm{mL}^{-1}\right)$, and mild (>0.05-0.40 $\mathrm{IU} \mathrm{mL}^{-1}$ ) haemophilia [19]. Educational level was categorized into three categories: primary and lower secondary, upper secondary and tertiary level. Age at time of first pregnancy was categorized into three categories: 16-25 years, 2630 years and $31-40$ years.

\section{Data analysis}

The associations between putative determinants and the choice for prenatal diagnosis were assessed by calculating the ratio of cumulative incidences, referred to as relative risks (RR) and 95\% confidence intervals (CI) in women who underwent early first trimester prenatal diagnosis and in women who underwent prenatal diagnosis later in pregnancy. Relative risks were adjusted for age at time of first pregnancy by the Mantel-Haenzel method. Factors considered to be associated with the choice for prenatal diagnosis are shown in Table 4 and 5. The subgroup of women who were carriers of severe haemophilia were analysed separately because we considered that their reasons to perform prenatal diagnosis were quite different from carriers of moderate and mild haemophilia. We did not correct for multiple testing, considering that valid associations would be missed by making adjustments for multiple testing [20].

Other survey data were analysed using descriptive statistical methods. Data are presented as medians and interquartile range (IQR) when not normally distributed.

\section{Results}

\section{Study population}

The characteristics of the study population are described in Table 1. Of the 207 women, 175 (85\%) women were carriers of haemophilia A, and the majority (84\%) had a positive family history of haemophilia. One hundred and three $(50 \%)$ women were carriers of severe haemophilia and $113(55 \%)$ carriers had one or more sons with haemophilia. The median age at time of the questionnaire was 41 years (IQR 35-39 years). One hundred and eight $(52 \%)$ women reported to adhere to a particular religion, including Roman Catholic $(n=52)$, Protestant $(n=51)$, Hindu $(n=3)$, Muslim $(n=1)$ and an unspecified religion $(n=1)$. Table 1 also shows the characteristics of the subgroups of carriers who underwent early prenatal diagnosis and carriers who underwent prenatal diagnosis later in pregnancy.

\section{Carriership diagnosis}

One hundred and sixteen (56\%) carriers were identified via DNA analysis, whereas for $70(34 \%)$ women the probability of carriership was calculated based on pedigree analysis and clotting factor levels. The remaining $21(10 \%)$ women did not remember the method of carrier testing. The median age at time of carrier testing was 30 years (IQR 26-35 years).

\section{Prevalence of prenatal diagnosis}

Of the 207 carriers, 112 women (54\%) underwent prenatal diagnosis during at least one pregnancy. Median age at time of first prenatal diagnosis was 29 years (IQR 26-32 years). Forty-eight women underwent early prenatal diagnosis via chorionic villus sampling or Y-PCR testing. In all pregnancies together, these women underwent 85 chorionic villus sampling and 5 Y-PCR testing procedures (Table 2). Sixty-four women underwent late prenatal diagnosis with ultrasound assessment or amniocentesis. In all their pregnancies, there were 78 ultrasound assessments and 27 amniocentesis procedures (Table 2). Prenatal diagnosis by cordocentesis was not reported by any of the women. One woman underwent pre-implantation genetic diagnosis for haemophilia.

Of the 112 women who underwent prenatal diagnosis, $58(52 \%)$ carriers were tested during more than one pregnancy. Thirty-three carriers underwent prenatal diagnosis during two pregnancies, of whom 30 (91\%) had the same prenatal test each time: ultrasound assessment $(n=22)$, chorionic villus sampling $(n=6)$ and amniocentesis $(n=2)$. Three women had different methods, of whom one switched from early to late prenatal diagnosis.

Twenty-five carriers underwent prenatal diagnosis during three pregnancies, of whom $20(80 \%)$ had the 
Table 1. Personal characteristics for all carriers of haemophilia $(n=207)$, for the carriers who had early prenatal diagnosis $(n=48)$ and the carriers who had late prenatal diagnosis $(n=64)$.

\begin{tabular}{|c|c|c|c|}
\hline & \multirow[b]{2}{*}{$\begin{array}{c}\text { All } \\
\text { carriers }\end{array}$} & \multicolumn{2}{|c|}{$\begin{array}{c}\text { Carriers who underwent } \\
\text { prenatal diagnosis }\end{array}$} \\
\hline & & $\begin{array}{c}\text { Early prenatal } \\
\text { diagnosis }\end{array}$ & $\begin{array}{c}\text { Late prenatal } \\
\text { diagnosis } \$\end{array}$ \\
\hline Number of women & 207 & 48 & 64 \\
\hline $\begin{array}{l}\text { Age at time of } \\
\text { questionnaire in years }\end{array}$ & $41(35-49)$ & $40(35-46)$ & $36(32-41)$ \\
\hline Missing data & 2 & 2 & 0 \\
\hline Number of pregnancies & $2.5(1-4)$ & $3(2-4)$ & $2(2-3)$ \\
\hline Missing data & 1 & 0 & 0 \\
\hline $\begin{array}{l}\text { Age at time of first } \\
\text { pregnancy }\end{array}$ & $26(24-26)$ & $28(25-28)$ & $27(25-27)$ \\
\hline \multicolumn{4}{|l|}{ Children $(\%)$} \\
\hline Yes & $205(99)$ & $47(98)$ & $64(100)$ \\
\hline No & $2(1)$ & $1(2)$ & $0(0)$ \\
\hline Number of children & $2(2-3)$ & $2(1-3)$ & $2(1-3)$ \\
\hline \multicolumn{4}{|l|}{ Marital status (\%) } \\
\hline $\begin{array}{l}\text { Married, including } \\
\text { registered partnership }\end{array}$ & $160(77)$ & $40(83)$ & $51(80)$ \\
\hline $\begin{array}{l}\text { Unmarried, including } \\
\text { single, divorced and } \\
\text { widowed women }\end{array}$ & $47(23)$ & $8(17)$ & $13(20)$ \\
\hline \multicolumn{4}{|l|}{ Religion (\%) } \\
\hline Yes & $108(52)$ & $18(38)$ & $35(55)$ \\
\hline No & $94(46)$ & $30(63)$ & $27(42)$ \\
\hline Missing data & $5(2)$ & $0(0)$ & $2(3)$ \\
\hline \multicolumn{4}{|c|}{ Highest completed educational levels } \\
\hline Primary level & $12(6)$ & $3(6)$ & 7 (11) \\
\hline Lower secondary level & $61(29)$ & $9(19)$ & $17(26)$ \\
\hline Upper secondary level & $78(38)$ & $18(38)$ & $24(38)$ \\
\hline Tertiary level & $54(26)$ & $17(35)$ & $16(24)$ \\
\hline Missing data & $2(1)$ & $1(2)$ & $0(0)$ \\
\hline \multicolumn{4}{|c|}{ Family history of haemophilia $^{\dagger}$} \\
\hline Yes & $174(84)$ & $41(85)$ & $54(84)$ \\
\hline No & $30(15)$ & $7(15)$ & $9(14)$ \\
\hline Missing data & $3(1)$ & $0(0)$ & $1(2)$ \\
\hline \multicolumn{4}{|l|}{ Son with haemophilia (\%) } \\
\hline Yes & $113(55)$ & $20(42)$ & $35(55)$ \\
\hline No & $94(45)$ & $28(58)$ & $29(45)$ \\
\hline \multicolumn{4}{|c|}{ Type of haemophilia in the family (\%) } \\
\hline Haemophilia A & $175(85)$ & $42(88)$ & $54(84)$ \\
\hline Haemophilia B & $21(10)$ & $4(8)$ & $6(9)$ \\
\hline Unknown/missing data & $11(5)$ & $2(4)$ & $4(6)$ \\
\hline \multicolumn{4}{|c|}{ Severity of haemophilia in the family (\%) } \\
\hline Severe & $103(50)$ & $40(83)$ & $29(45)$ \\
\hline Moderate & $28(14)$ & $5(10)$ & $11(17)$ \\
\hline Mild & $50(24)$ & $1(2)$ & $14(22)$ \\
\hline Unknown/missing data & $26(12)$ & $2(4)$ & $10(15)$ \\
\hline \multicolumn{4}{|c|}{ Times opted for prenatal diagnosis } \\
\hline Never & $95(46)$ & $0(0)$ & $0(0)$ \\
\hline One time & $54(26)$ & $22(46)$ & $32(50)$ \\
\hline Two times & $33(16)$ & $10(21)$ & $23(36)$ \\
\hline Three times & $25(12)$ & $16(33)$ & $9(14)$ \\
\hline
\end{tabular}

Values are presented as numbers (\%) of the no. of women or medians (interquartile range) when appropriate.

${ }^{\dagger}$ Defined as in extended family members, not including son(s).

"Early prenatal diagnosis includes chorionic villus sampling and Y-PCR testing.

${ }^{\$}$ Late prenatal diagnosis includes ultrasound assessment and amniocentesis.

same method for prenatal diagnosis each time: chorionic villus sampling $(n=14)$, ultrasound assessment $(n=5)$ and amniocentesis $(n=1)$. Five carriers had different tests, of whom three switched from late to early prenatal diagnosis and two from early to late prenatal diagnosis. Frequencies of the prenatal diagnosis methods applied
Table 2. Used methods and outcomes for prenatal diagnosis executed for a first, second or third time.

\begin{tabular}{|c|c|c|c|c|}
\hline & \multicolumn{3}{|c|}{ Use of prenatal diagnosis } & \multirow[b]{2}{*}{$\begin{array}{c}\text { Total } \\
(n=195)\end{array}$} \\
\hline & $\begin{array}{l}\text { 1st time } \\
(n=112)\end{array}$ & $\begin{array}{l}\text { 2nd time } \\
(n=58)\end{array}$ & $\begin{array}{l}\text { 3rd time } \\
(n=25)\end{array}$ & \\
\hline \multicolumn{5}{|l|}{ Methods of prenatal diagnosis } \\
\hline Early prenatal diagnosis & $46(41)$ & $26(45)$ & $18(72)$ & $90(46)$ \\
\hline Chorionic villus sampling & $43(38)$ & $25(43)$ & $17(68)$ & $85(43)$ \\
\hline $\begin{array}{l}\text { Foetal gender assessment } \\
\text { via Y-PCR testing }\end{array}$ & $3(3)$ & $1(2)$ & $1(4)$ & $5(3)$ \\
\hline Late prenatal diagnosis & $66(59)$ & $32(56)$ & $7(28)$ & $105(54)$ \\
\hline $\begin{array}{l}\text { Foetal gender assessment } \\
\text { via ultrasound }\end{array}$ & $49(44)$ & $27(47)$ & $2(8)$ & $78(40)$ \\
\hline Amniocentesis & $17(15)$ & $5(9)$ & $5(20)$ & $27(14)$ \\
\hline \multicolumn{5}{|c|}{ Outcomes of prenatal diagnosis } \\
\hline Daughter & $59(53)$ & $24(41)$ & $9(36)$ & $92(47)$ \\
\hline Son with unknown status & $30(27)$ & $16(28)$ & $3(12)$ & $49(25)$ \\
\hline Son without haemophilia & $9(8)$ & $10(17)$ & $3(12)$ & $22(11)$ \\
\hline $\begin{array}{l}\text { Affected son with } \\
\text { haemophilia }\end{array}$ & $10(9)$ & $8(14)$ & $8(32)$ & $26(13)$ \\
\hline Others* & $4(3)$ & $0(0)$ & $2(8)$ & $6(3)$ \\
\hline $\begin{array}{c}\text { Termination of } \\
\text { pregnancy for } \\
\text { haemophilia }\end{array}$ & $6(5)$ & $8(14)$ & $4(16)$ & $18(9)$ \\
\hline
\end{tabular}

for the first and second time were similar. For the third time, however, the percentage of early prenatal diagnosis $(72 \%)$ was higher as compared to the first $(40 \%)$ and second $(45 \%)$ time of testing. Of the 17 women who underwent chorionic villus sampling for a third time, a majority $(82 \%)$ underwent chorionic villus sampling the previous two times of prenatal diagnosis.

Of the women who never had prenatal diagnosis, three $(3 \%)$ women indicated they would choose for either invasive or non-invasive prenatal diagnosis in a future pregnancy, $56(59 \%)$ would not and 36 (38\%) did not know yet.

In the subgroup of carriers of severe haemophilia the prevalence of prenatal diagnosis was 67\% (69 of 103). Of these 69 carriers, 40 women underwent early prenatal diagnosis and 29 women prenatal diagnosis later in pregnancy.

\section{Outcomes of prenatal diagnosis}

Early prenatal diagnosis via chorionic villus sampling or Y-PCR testing was applied in 90 pregnancies. In 22 pregnancies chorionic villus sampling was positive for a male foetus with haemophilia, and in 18 (82\%) of these pregnancies termination of pregnancy was opted for (Table 3). Seventeen of these cases concerned severe haemophilia and the other case involved moderate haemophilia. Three women had terminations of two pregnancies of a male foetus with haemophilia, and these women were all carriers of severe haemophilia. Of the four pregnancies with an affected foetus that were continued to term, three had severe haemophilia and one had moderate haemophilia. 
Table 3. Termination of pregnancy for pregnancies positive for haemophilia according to early or late prenatal diagnosis.

\begin{tabular}{lccc}
\hline & & \multicolumn{2}{c}{ Prenatal diagnosis } \\
\cline { 3 - 4 } & & Early & Late \\
\hline Termination of & Yes & $18^{*}(82)$ & $0(0)$ \\
pregnancy & No & $4(18)$ & $4(100)$ \\
Total number of & & 22 & 4 \\
affected pregnancies & & &
\end{tabular}

Values are presented as numbers (\%) of the no. of pregnancies.

*Three carriers underwent the procedure for termination of pregnancy two times.

There were 105 pregnancies in which late prenatal diagnosis was applied. In 27 pregnancies invasive prenatal diagnosis was applied. Of these, four $(4 \%)$ pregnancies were positive for a son with haemophilia. Three of these positive tested pregnancies were demonstrated by amniocentesis following ultrasound assessment, and one pregnancy by amniocentesis only. All four affected pregnancies were continued to term. Of these, two had severe, one had moderate and one had mild haemophilia.

Seven women had termination of pregnancy for reasons other than haemophilia, including termination of pregnancy for a male foetus with trisomy 21 , and termination of pregnancy for a female foetus with Turner syndrome and haemophilia.

\section{Reported reasons pro and against prenatal diagnosis}

Among the women who underwent early prenatal diagnosis, the most frequently reported reasons to undergo prenatal diagnosis were: the carrier's preference to know if she was pregnant of a child with haemophilia (93\%), because of an increased risk for a child with a congenital disorder other than haemophilia $(3 \%)$, the physician's preference to know the haemophilia status of the child $(2 \%)$ and other reasons $(2 \%)$.

Women who underwent late prenatal diagnosis reported the following reasons to undergo prenatal diagnosis: the carrier's preference to know if she was pregnant with a child with haemophilia $(41 \%)$, the physician's preference to know the haemophilia status of the child $(32 \%)$, because of an increased risk for a child with a congenital disorder other than haemophilia $(8 \%)$ and other reasons $(20 \%)$.

Among the 95 women who never had prenatal diagnosis, the four most cited reasons were: accepting the possibility of having a child with haemophilia $(28 \%)$, fear for foetal loss due to prenatal diagnosis $(16 \%)$, being opposed to undergo termination of pregnancy $(14 \%)$ and perceiving the haemophilia in the family as not severe enough $(13 \%)$. Less frequently reported reasons were: fear for foetal damage due to prenatal testing $(11 \%)$, finding haemophilia not a good reason for prenatal diagnosis $(6 \%)$, not being aware of the possibility of prenatal diagnosis $(6 \%)$, because of religious belief $(4 \%)$, because the partner was against prenatal diagnosis $(2 \%)$ and finding the risk of having an affected child too small $(2 \%)$.
For carriers of severe haemophilia the reported pros and cons for prenatal diagnosis were similar. Reported reasons for prenatal diagnosis were: the carrier's preference to know if she was pregnant of a child with haemophilia $(80 \%)$, the physician's preference to know the haemophilia status of the child $(9 \%)$, because of an increased risk for a child with a congenital disorder other than haemophilia $(6 \%)$ and other reasons $(5 \%)$. The following reasons con prenatal diagnosis reported by carriers of severe haemophilia were: accepting the possibility of having a child with haemophilia $(31 \%)$, fear for foetal loss due to prenatal diagnosis $(20 \%)$, being opposed to undergo termination of pregnancy $(16 \%)$, fear for foetal damage due to prenatal testing $(12 \%)$, not being aware of the possibility of prenatal diagnosis $(5 \%)$, finding haemophilia not a good reason for prenatal diagnosis $(5 \%)$, because the partner was against prenatal diagnosis $(3 \%)$, perceiving the haemophilia in the family not severe enough $(3 \%)$, because of religious belief $(3 \%)$ and finding the risk of having an affected child too small $(2 \%)$.

\section{Factors associated with decisions for prenatal diagnosis}

Table 4 presents the associations of several determinants with the choice for early prenatal diagnosis and the choice for late prenatal diagnosis in all carriers. The choice for early prenatal diagnosis was associated with: a liberal view towards termination of pregnancy, severe haemophilia in the family and having no religion. Compared to women aged 16-25 years at time of first pregnancy, older women (26-30 years and 3140 years) opted more often for prenatal diagnosis.

Smaller positive associations were found for being married, presence of a previous child with haemophilia, a higher educational level and a higher bleeding score. Year of birth and having family members with haemophilia did not influence the choice for early prenatal diagnosis. After adjustment for age at time of first pregnancy, the adjusted relative risks did not differ from the crude relative risks.

The choice for late prenatal diagnosis was associated with two determinants: a previous child with haemophilia and year of birth. Women born after 1970 were 2.3 times (CI 1.5-3.5) more likely to undergo late prenatal diagnosis than women born before 1970. In contrast, women with a liberal view towards termination of pregnancy tended to opt less often for late prenatal diagnosis.

Total number of pregnancies, total number of children, family relationship to nearest family member with haemophilia and the perceived importance of haemophilia in family planning were not associated with the choice for prenatal diagnosis (data not shown).

Association between potential determinants and testing among carriers of severe haemophilia are shown in 
Table 4. Determinants influencing the choice for prenatal diagnosis made by all carriers of haemophilia $(n=207)$.

\begin{tabular}{|c|c|c|c|c|c|c|c|c|}
\hline \multirow[b]{3}{*}{ Determinant } & \multicolumn{8}{|c|}{ All carriers } \\
\hline & \multicolumn{3}{|c|}{ Prenatal diagnosis } & \multirow[b]{2}{*}{ Total } & \multicolumn{2}{|c|}{ Early prenatal diagnosis $\$$} & \multicolumn{2}{|c|}{ Late prenatal diagnosis" } \\
\hline & $\begin{array}{c}\text { Early }^{\S} \\
(n=48)\end{array}$ & $\begin{array}{l}\text { Late } \\
(n=64)\end{array}$ & $\begin{array}{c}\text { No } \\
(n=95)\end{array}$ & & $\begin{array}{l}\text { Crude } \\
\text { RR (CI) }\end{array}$ & $\begin{array}{l}\text { Adjusted } \\
\mathrm{RR}^{*}(\mathrm{CI})\end{array}$ & $\begin{array}{l}\text { Crude } \\
\text { RR (CI) }\end{array}$ & $\begin{array}{l}\text { Adjusted } \\
\mathrm{RR}^{*}(\mathrm{CI})\end{array}$ \\
\hline \multicolumn{9}{|l|}{ Marital status } \\
\hline Unmarried** & $8(17)$ & $13(28)$ & $26(55)$ & 47 & 1 (ref) & 1 (ref) & 1 (ref) & 1 (ref) \\
\hline Married & $40(25)$ & $51(32)$ & $69(43)$ & 160 & $1.5(0.7-2.9)$ & $1.4(0.7-2.8)$ & $1.2(0.7-2.0)$ & $1.1(0.7-1.9)$ \\
\hline \multicolumn{9}{|c|}{ Age at time of first pregnancy } \\
\hline $16-25$ years & $14(16)$ & $24(28)$ & $48(56)$ & 86 & 1 (ref) & NA & 1 (ref) & NA \\
\hline $26-30$ years & $23(28)$ & $26(31)$ & $34(41)$ & 83 & $1.7(0.9-3.1)$ & NA & $1.1(0.7-1.8)$ & NA \\
\hline $31-40$ years & $11(32)$ & $14(41)$ & $9(27)$ & 34 & $2.0(1.0-3.9)$ & NA & $1.5(0.9-2.5)$ & NA \\
\hline \multicolumn{9}{|l|}{ Year of birth } \\
\hline Before 1970 & $37(22)$ & $42(26)$ & $85(52)$ & 164 & 1 (ref) & 1 (ref) & 1 (ref) & 1 (ref) \\
\hline After 1970 & $9(22)$ & $22(54)$ & $10(24)$ & 41 & $1.0(0.5-1.9)$ & $1.0(0.5-2.0)$ & $2.1(1.4-3.1)$ & $2.3(1.5-3.5)$ \\
\hline \multicolumn{9}{|c|}{ Highest completed educational level } \\
\hline $\begin{array}{l}\text { Primary/lower } \\
\text { secondary level }\end{array}$ & $12(16)$ & $24(33)$ & $37(51)$ & 73 & 1 (ref) & 1 (ref) & 1 (ref) & 1 (ref) \\
\hline Upper secondary level & $18(23)$ & $24(31)$ & $36(46)$ & 78 & $1.4(0.7-2.7)$ & $1.4(0.7-2.9)$ & $0.9(0.6-1.5)$ & $0.9(0.5-1.4)$ \\
\hline Tertiary level & $17(31)$ & $16(30)$ & $21(39)$ & 54 & $1.9(1.0-3.7)$ & $1.7(0.7-4.4)$ & $0.9(0.5-1.5)$ & $0.8(0.4-1.4)$ \\
\hline \multicolumn{9}{|l|}{ Religion } \\
\hline Yes & $18(17)$ & $35(33)$ & $54(50)$ & 107 & 1 (ref) & 1 (ref) & 1 (ref) & 1 (ref) \\
\hline No & $30(32)$ & $27(29)$ & $37(39)$ & 94 & $1.9(1.1-3.2)$ & $1.9(1.1-3.1)$ & $0.9(0.6-1.3)$ & $0.8(0.5-1.2)$ \\
\hline \multicolumn{9}{|c|}{ View regarding termination for pregnancy for haemophilia } \\
\hline Neutral & $2(5)$ & $13(33)$ & $25(63)$ & 40 & 1 (ref) & 1 (ref) & 1 (ref) & 1 (ref) \\
\hline $\begin{array}{l}\text { Against termination } \\
\text { of pregnancy }\end{array}$ & $0(0)$ & $32(46)$ & $37(54)$ & 69 & 0 & 0 & $1.4(0.9-2.4)$ & $1.3(0.8-2.3)$ \\
\hline $\begin{array}{l}\text { Not against termination } \\
\text { of pregnancy }\end{array}$ & $40(63)$ & $12(19)$ & $12(19)$ & 64 & $12.5(3.2-48.9)$ & $12.5(3.1-51.2)$ & $0.6(0.3-1.1)$ & $0.6(0.3-1.2)$ \\
\hline \multicolumn{9}{|l|}{ Bleeding score } \\
\hline 0 & $15(19)$ & $24(30)$ & $41(51)$ & 80 & 1 (ref) & 1 (ref) & 1 (ref) & 1 (ref) \\
\hline 1 & $18(23)$ & $25(32)$ & $34(44)$ & 77 & $1.2(0.7-2.3)$ & $1.2(0.7-2.3)$ & $1.1(0.7-1.7)$ & $1.1(0.7-1.7)$ \\
\hline $2-4$ & $15(30)$ & $15(30)$ & $20(40)$ & 50 & $1.6(0.9-3.0)$ & $1.6(0.9-3.0)$ & $1.0(0.6-1.7)$ & $1.0(0.6-1.7)$ \\
\hline \multicolumn{9}{|c|}{ Severity of haemophilia in family } \\
\hline Mild & $1(2)$ & $14(28)$ & $35(70)$ & 50 & 1 (ref) & 1 (ref) & 1 (ref) & 1 (ref) \\
\hline Moderate & $5(18)$ & $11(39)$ & $12(43)$ & 28 & $8.9(1.1-72.7)$ & $8.3(1.1-65.5)$ & $1.4(0.7-2.7)$ & $1.4(0.8-2.7)$ \\
\hline Severe & $40(39)$ & $29(28)$ & $34(33)$ & 103 & $19.4(2.7-137.2)$ & $20.2(2.7-153.6)$ & $1.0(0.6-1.7)$ & $0.9(0.5-1.6)$ \\
\hline \multicolumn{9}{|c|}{ Family members with haemophilia ${ }^{\dagger}$} \\
\hline No & $7(23)$ & $9(30)$ & $14(47)$ & 30 & 1 (ref) & 1 (ref) & 1 (ref) & 1 (ref) \\
\hline Yes & $41(24)$ & $54(31)$ & $79(45)$ & 174 & $1.0(0.5-2.0)$ & $0.9(0.5-1.9)$ & $1.0(0.6-1.9)$ & $1.0(0.6-1.9)$ \\
\hline \multicolumn{9}{|c|}{ Previous child with haemophilia } \\
\hline No & $39(21)$ & $50(27)$ & $94(51)$ & 183 & 1 (ref) & 1 (ref) & 1 (ref) & 1 (ref) \\
\hline Yes & $9(38)$ & $14(58)$ & $1(4)$ & 24 & $1.8(1.0-3.2)$ & $1.9(1.1-3.5)$ & $2.1(1.4-3.2)$ & $2.2(1.4-3.4)$ \\
\hline \multicolumn{9}{|c|}{ Family members with treatment-related viral infections ${ }^{\ddagger}$} \\
\hline No & $21(16)$ & $41(32)$ & $67(52)$ & 129 & 1 (ref) & 1 (ref) & 1 (ref) & 1 (ref) \\
\hline Yes & $27(35)$ & $23(30)$ & $28(36)$ & 78 & $2.1(1.3-3.5)$ & $2.1(1.3-3.4)$ & $0.9(0.6-1.4)$ & $0.9(0.6-1.4)$ \\
\hline
\end{tabular}

Values are presented as numbers $(\%)$ of the no. of women.

*Adjusted for age at time of first pregnancy.

†Not including son(s).

${ }^{\ddagger} \mathrm{HIV}$ or hepatitis infection, including in deceased family members.

${ }^{\$}$ Early prenatal diagnosis includes Y-PCR testing and chorionic villus sampling.

"Late prenatal diagnosis includes ultrasound assessment and amniocentesis.

**Including single, divorced and widowed women.

CVS, chorionic villus sampling; 95\% CI, confidence interval; NA, not applicable, Ref, reference; RR, relative risk.

Table 5. The findings among carriers of severe haemophilia did not substantially differ from those among all carriers. However, among carriers of severe haemophilia higher bleeding score, higher educational level, and having family members with treatment-related viral infections did not show any association with early prenatal diagnosis.

\section{Discussion}

In this nationwide cross-sectional study among 207 Dutch carriers of a factor VIII or IX gene mutation, 112 $(54 \%)$ women had chosen for prenatal diagnosis of haemophilia. Forty-eight $(23 \%)$ carriers had undergone early prenatal diagnosis via Y-PCR testing or chorionic villus sampling in the first trimester. In these women 22 pregnancies were positive for an affected male foetus, and in $18(82 \%)$ of these cases the pregnancy was terminated. A liberal view towards termination of pregnancy, severe haemophilia in the family, older age at time of first pregnancy and having no religion were associated with the choice for first trimester prenatal diagnosis. Sixtyfour $(31 \%)$ carriers had prenatal diagnosis later during pregnancy via amniocentesis or ultrasound assessment. Among these, four pregnancies were positive for haemo- 
Table 5. Determinants influencing the choice for prenatal diagnosis made by carriers of severe haemophilia $(n=103)$.

\begin{tabular}{|c|c|c|c|c|c|c|c|c|}
\hline \multirow[b]{3}{*}{ Determinant } & \multicolumn{8}{|c|}{ Severe carriers } \\
\hline & \multicolumn{3}{|c|}{ Prenatal diagnosis } & \multirow[b]{2}{*}{ Total } & \multicolumn{2}{|c|}{ Early prenatal diagnosis $\$$} & \multicolumn{2}{|c|}{ Late prenatal diagnosis } \\
\hline & $\begin{array}{l}\text { Early }^{\S} \\
(n=40)\end{array}$ & $\begin{array}{l}\text { Late }^{\sigma} \\
(n=29)\end{array}$ & $\begin{array}{c}\text { No } \\
(n=34)\end{array}$ & & $\begin{array}{l}\text { Crude } \\
\text { RR (CI) }\end{array}$ & $\begin{array}{l}\text { Adjusted } \\
\mathrm{RR}^{*}(\mathrm{CI})\end{array}$ & $\begin{array}{l}\text { Crude } \\
\text { RR (CI) }\end{array}$ & $\begin{array}{l}\text { Adjusted } \\
\mathrm{RR} *(\mathrm{CI})\end{array}$ \\
\hline \multicolumn{9}{|l|}{ Marital status } \\
\hline Unmarried** & $6(26)$ & $5(22)$ & $12(52)$ & 23 & 1 (ref) & 1 (ref) & 1 (ref) & 1 (ref) \\
\hline Married & $34(43)$ & $24(30)$ & $22(28)$ & 80 & $1.6(0.8-3.4)$ & $1.5(0.7-3.1)$ & $1.4(0.6-3.2)$ & $1.3(0.5-3.2)$ \\
\hline \multicolumn{9}{|c|}{ Age at time of first pregnancy } \\
\hline $16-25$ years & $12(29)$ & $10(24)$ & $19(46)$ & 41 & 1 (ref) & NA & 1 (ref) & NA \\
\hline $26-30$ years & $17(46)$ & $11(30)$ & $9(24)$ & 37 & $1.6(0.9-2.8)$ & NA & $1.2(0.6-2.5)$ & NA \\
\hline $31-40$ years & $11(46)$ & $8(33)$ & $5(21)$ & 31 & $1.6(0.8-3.0)$ & NA & $1.4(0.6-3.0)$ & NA \\
\hline \multicolumn{9}{|l|}{ Year of birth } \\
\hline Before 1970 & $33(40)$ & $20(24)$ & $30(36)$ & 83 & 1 (ref) & 1 (ref) & 1 (ref) & 1 (ref) \\
\hline After 1970 & $6(32)$ & $9(47)$ & $4(21)$ & 19 & $0.8(0.4-1.6)$ & $0.9(0.4-1.8)$ & $2.0(1.1-3.6)$ & $2.4(1.2-4.8)$ \\
\hline \multicolumn{9}{|c|}{ Highest completed educational level } \\
\hline $\begin{array}{l}\text { Primary/lower } \\
\text { secondary level }\end{array}$ & $11(34)$ & $7(22)$ & $14(44)$ & 32 & 1 (ref) & 1 (ref) & 1 (ref) & 1 (ref) \\
\hline Upper secondary level & $13(30)$ & $15(34)$ & $16(36)$ & 44 & $0.9(0.4-1.7)$ & $0.9(0.4-1.8)$ & $1.6(0.7-3.4)$ & $1.5(0.7-3.5)$ \\
\hline Tertiary level & $16(62)$ & $7(27)$ & $3(12)$ & 26 & $1.8(1.0-3.2)$ & $1.9(0.8-4.9)$ & $1.2(0.5-3.1)$ & $1.4(0.5-4.4)$ \\
\hline \multicolumn{9}{|l|}{ Religion } \\
\hline Yes & $16(33)$ & $15(31)$ & $18(37)$ & 49 & 1 (ref) & 1 (ref) & 1 (ref) & 1 (ref) \\
\hline No & $24(47)$ & $14(27)$ & $13(25)$ & 51 & $1.4(0.8-2.4)$ & $1.4(0.8-2.4)$ & $0.9(0.5-1.7)$ & $0.8(0.5-1.6)$ \\
\hline \multicolumn{9}{|c|}{ View regarding termination of pregnancy for haemophilia } \\
\hline Neutral & $1(6)$ & $4(22)$ & $13(72)$ & 18 & 1 (ref) & 1 (ref) & 1 (ref) & 1 (ref) \\
\hline $\begin{array}{l}\text { Against termination } \\
\text { of pregnancy }\end{array}$ & $0(0)$ & $15(54)$ & $13(46)$ & 28 & 0 & 0 & $2.4(1.0-6.2)$ & $2.2(0.8-6.2)$ \\
\hline $\begin{array}{l}\text { Not against termination } \\
\text { of pregnancy }\end{array}$ & $33(79)$ & $6(14)$ & $3(7)$ & 42 & $14.1(2.1-95.6)$ & $14.9(1.8-121.0)$ & $0.6(0.2-2.0)$ & $0.7(0.2-2.3)$ \\
\hline \multicolumn{9}{|l|}{ Bleeding score } \\
\hline 0 & $13(35)$ & $11(30)$ & $13(35)$ & 37 & 1 (ref) & 1 (ref) & 1 (ref) & 1 (ref) \\
\hline 1 & $16(42)$ & $11(29)$ & $11(29)$ & 38 & $1.2(0.7-2.1)$ & $1.2(0.7-2.2)$ & $1.0(0.5-2.0)$ & $1.0(0.5-2.1)$ \\
\hline $2-4$ & $11(39)$ & $7(25)$ & $10(36)$ & 28 & $1.1(0.6-2.1)$ & $1.1(0.6-2.0)$ & $0.8(0.4-1.9)$ & $0.9(0.4-2.0)$ \\
\hline \multicolumn{9}{|c|}{ Family members with haemophilia ${ }^{\dagger}$} \\
\hline No & $6(25)$ & $7(29)$ & $11(46)$ & 24 & 1 (ref) & 1 (ref) & 1 (ref) & 1 (ref) \\
\hline Yes & $34(43)$ & $22(28)$ & $23(29)$ & 79 & $1.7(0.8-3.6)$ & $1.9(0.9-3.8)$ & $1.0(0.5-2.0)$ & $1.1(0.5-2.3)$ \\
\hline \multicolumn{9}{|c|}{ Previous child with haemophilia } \\
\hline No & $32(37)$ & $21(24)$ & $33(38)$ & 86 & 1 (ref) & 1 (ref) & 1 (ref) & 1 (ref) \\
\hline Yes & $8(47)$ & $8(47)$ & $1(6)$ & 17 & $1.3(0.7-2.2)$ & $1.4(0.7-2.5)$ & $1.9(1.0-3.6)$ & $1.9(1.0-3.7)$ \\
\hline \multicolumn{9}{|c|}{ Family members with treatment-related viral infections ${ }^{*}$} \\
\hline No & $18(33)$ & $17(32)$ & $19(35)$ & 54 & 1 (ref) & 1 (ref) & 1 (ref) & 1 (ref) \\
\hline Yes & $22(45)$ & $12(24)$ & $15(31)$ & 49 & $1.3(0.8-2.2)$ & $1.3(0.8-2.1)$ & $0.8(0.4-1.5)$ & $0.8(0.4-1.4)$ \\
\hline
\end{tabular}

Values are presented as numbers (\%) of the no. of women.

*Adjusted for age at time of first pregnancy.

${ }^{\dagger}$ Not including son(s).

${ }^{\star} \mathrm{HIV}$ or Hepatitis infection, including in deceased family members.

${ }^{\$}$ Early prenatal diagnosis includes Y-PCR testing and chorionic villus sampling.

"Late prenatal diagnosis includes ultrasound assessment and amniocentesis.

* Including single, divorced and widowed women.

CVS, chorionic villus sampling; 95\% CI, confidence interval; Ref, reference; RR, relative risk.

philia, and all four were continued to term. A previous child with haemophilia and year of birth were associated with the choice for late prenatal diagnosis.

To appreciate these findings, several limitations need to be considered. First, a self-reported postal questionnaire may be influenced by recall bias, which may lead to underestimation of the proportion of women undergoing prenatal diagnosis. However, considering the emotional stress accompanying Y-PCR testing, chorionic villus sampling, amniocentesis and the decision to terminate an affected pregnancy, invasive prenatal testing procedures are not likely to be forgotten. Also, this is not likely to be associated with determinants of choosing for prenatal diagnosis. Ultrasound assessment, however, may have been underreported so that the prevalence of non-invasive prenatal testing via ultrasound assessment may be underestimated. In addition, ultrasound assessments as reported by the carriers may have been performed for reasons other than prenatal diagnosis of haemophilia. Although there is an open attitude towards termination of affected pregnancies in the Netherlands, we cannot completely rule out that there was an underreporting of termination of pregnancies. Second, the determinants affecting the choice for prenatal testing were measured after the actual choice for prenatal diagnosis, and determinants may have changed over time and differ at the time of choosing for prenatal diagnosis. Still, attitudes towards prenatal diagnosis and termination of pregnancy are likely to remain stable over time [21]. Third, our study results involved women who 
underwent carrier testing in the Netherlands during the period 1992-2004. Since then, advances in prenatal diagnosis have been made, particularly in the development of non-invasive foetal gender determination via analysis of free foetal DNA obtained from maternal blood. In addition, treatment options for haemophilia have improved over the years. This should be taken into account when our results are translated into clinical implications for current-day practice.

A strength of our study is its relatively high responserate of $71 \%$. The results of the survey are therefore likely to be representative for all carriers of haemophilia in the Netherlands at time of this study. Selection bias is not likely to have influenced our results, however, we cannot exclude this.

A majority $(54 \%)$ of the carriers underwent carrier testing for haemophilia in view of family planning. However, in our study carriers had an average of two children. This figure is comparable with women in the general Dutch population in the same period, for whom the mean number of children during the same period was two (Statistics Netherlands; http://statline. cbs.nl). These figures are also in line with data from Sweden, in which carriers were found to have the same number of children as other women of similar age [21]. Also, mean age at time of first pregnancy did not differ between carriers and women in the general Dutch population (27 years vs. 28 years respectively).

Women who underwent chorionic villus sampling and $\mathrm{Y}$ PCR testing likely had the intention to terminate an affected pregnancy. Indeed, in our study these women had undergone termination of pregnancy in a substantial proportion $(82 \%)$ of the affected pregnancies. Only four $(18 \%)$ women undergoing chorionic villus sampling decided to continue their affected pregnancy to term. In addition, the choice for chorionic villus sampling and Y-PCR testing was strongly associated with a liberal view towards termination of pregnancy. In contrast, ultrasound assessment and amniocentesis are rather applied to assess the need for precautions during pregnancy and delivery. In concordance with this view, in our study none of the women who underwent late prenatal diagnosis had termination of pregnancy for a pregnancy affected with haemophilia.

The majority $(85 \%)$ of our study group had known haemophilia in the family. Therefore, the results may not be directly applicable to sporadic carriers of haemophilia. These women may differ from the sporadic carriers in their choices, attitudes and determinants of prenatal diagnosis.

During the 12 year-study period the availability and accepted practice of the different methods of prenatal diagnosis have evolved. For instance, foetal gender determination by Y-PCR testing has become available only in the last few years. Despite these changes, a majority $(86 \%)$ of the women who underwent prenatal diagnosis for more than one pregnancy had the same method of prenatal diagnosis each time.
The prevalence of prenatal diagnosis found in this study is not directly comparable with figures found in previous studies due to differences in both the study population and the applied definition of prenatal diagnosis. Including only chorionic villus sampling, in our study the proportion of women who opted for prenatal diagnosis was $22 \%$. In a Dutch survey conducted in 1987 among 218 obligate and potential carriers who had ever been pregnant, $11 \%$ had opted for invasive prenatal diagnosis, and $31 \%$ would have opted for prenatal diagnosis if termination between the 8th and 10th week of pregnancy could be realized [13]. In Sweden, 14\% of 376 known carriers in 1994 underwent prenatal diagnosis by foetal blood sampling or by chorionic villus sampling [21]. In 1996, a survey held in London among 197 obligate and potential carriers of haemophilia reported that 36 out of 160 $(23 \%)$ women who had been pregnant had opted for invasive prenatal diagnosis [15]. It seems that the proportion of carriers opting for invasive prenatal diagnosis with the aim to undergo termination of pregnancy in case of haemophilia found in our study is comparable with that from previous studies, despite developments in genetic counselling and prenatal diagnosis. First, the availability of prenatal diagnosis has become more widespread, and carriers may be better informed about prenatal diagnosis for haemophilia. Second, Y-PCR testing in early pregnancy may prelude chorionic villus sampling in case of a female foetus. On the other hand, the demand for early invasive prenatal diagnosis with the aim of preventing the birth of a child with haemophilia may have decreased because of improved treatment options and a lowered perceived disease severity for haemophilia [21]. In our study, 39 women did not opt for prenatal diagnosis because they either accepted the possibility of a child with haemophilia or they did not find haemophilia a sufficiently severe disease. A decrease in invasive testing has been shown in two studies among English carriers, in whom the percentage of invasive prenatal diagnosis for haemophilia decreased from $35 \%$ during $1985-1995$ to $20 \%$ in $1995-2005$ $[22,23]$. The frequency of invasive prenatal diagnosis for haemophilia may decrease further, when foetal gender determination by non-invasive methods such as Y-PCR testing in maternal blood is introduced on a large scale [24,25]. In addition, pre-implantation genetic diagnosis may serve as an alternative for prenatal diagnosis, although this procedure requires in vitro fertilization that is still associated with disadvantages at the moment [26]. Sperm sorting for $\mathrm{X}$-carrying sperm may be another alternative method to avoid an affected pregnancy [27]. Moreover, current research is directed to develop non-invasive tests to diagnose the gene mutation causing haemophilia directly in free foetal DNA obtained from maternal blood [28]. 
The proportion of carriers undergoing ultrasound assessment in our study was $21 \%$. This proportion is quite low, considering that currently every carrier in the Netherlands is offered ultrasound assessment to allow planning of the management during delivery. Also, offering amniocentesis in the third trimester for obstetric reasons has been a recent development. In concordance with this view, women born after 1970 tended to have ultrasound assessment and amniocentesis more frequently. Ultrasound for gender determination is now advised to all carriers who did not have early prenatal diagnosis.

In the present study a number of determinants were associated with the choice for prenatal diagnosis. Several of these determinants associated with the choice for prenatal diagnosis were previously described by others, such as having a liberal view towards termination of pregnancy, perceiving haemophilia as a severe disease and adhering to a religion [13,21].

In conclusion, we have described the prevalence, methods and outcomes of prenatal diagnosis and several determinants of the choice of prenatal diagnosis made by female carriers of haemophilia. Our results will be helpful in improving the genetic counselling given to carriers at increased risk of having a child with haemophilia.

\section{Acknowledgements}

We would like to thank all the women who have participated in this study. In addition, we would like to thank I. de Jonge and I. Noordermeer for their assistance in data management. We are grateful to Dr R.A. Kadir for her comments on the manuscript.

\section{Author contributions}

I.P., E.M-B., A.V., J.vD-H., F.R. and J.vdB. participated in designing the research; I.P., E.M-B., F.R., and J.vdB. collected the data; D.B., S.G. and J.vdB. analysed data and wrote the article; and all authors checked the final version of the manuscript.

\section{Disclosures}

SCG has received unrestricted research support from ZLB Behring, NovoNordisk, Wyeth, Baxter and Bayer. JGvdB has received unrestricted research/educational funding for various projects from the following companies: Bayer Schering Pharma, Baxter, ZLB Behring, NovoNordisk and Wyeth. She has also been a consultant to Baxter and Wyeth and she has been a teacher on educational activities for Bayer Schering Pharma.

\section{References}

1 Mannucci PM, Tuddenham EG. The hemophilias - from royal genes to gene therapy. $N$ Engl J Med 2001; 344: 1773-9.

2 Bolton-Maggs PH, Pasi KJ. Haemophilias A and B. Lancet 2003; 361: 1801-9.

3 Graw J, Brackmann HH, Oldenburg J, Schneppenheim R, Spannagl M, Schwaab R. Haemophilia A: from mutation analysis to new therapies. Nat Rev Genet 2005; 6: 488501.

4 Mannucci PM. Back to the future: a recent history of haemophilia treatment. Haemophilia 2008; 14(Suppl. 3): 10-8.

5 Meijer K, Bouman K, Sollie KM, Tamminga RY, van der Meer J. [Management of pregnancy and childbirth in carriers of haemophilia]. Ned Tijdschr Geneeskd 2008; 152: 1249-53.

6 Leebeek FWG, Page-Christiaens GCML, Vriends AHJT, Mauser-Bunschoten EP. Draagsters van hemofilie: bloedingsneiging, prenatale diagnostiek, zwangerschap en bevalling. In: Leebeek FWG, Mauser-Bunschoten EP eds. Richtlijn en behandeling van hemofilie en aanverwante hemostasestoornisse. Alphen aan den Rijn: Van Zuiden Communications B.V, 2009: 39-49.

7 Tabor A, Alfirevic Z. Update on procedurerelated risks for prenatal diagnosis techniques. Fetal Diagn Ther 2010; 27: 1-7.

8 Ljung RC. Prenatal diagnosis of haemophilia. Haemophilia 1999; 5: 84-7.

9 Lee CA, Chi C, Pavord SR et al. The obstetric and gynaecological management of women with inherited bleeding disorders review with guidelines produced by a taskforce of UK Haemophilia Centre Doctors' Organization. Haemophilia 2006; 12: 30136.
10 Honda H, Miharu N, Ohashi Y et al. Fetal gender determination in early pregnancy through qualitative and quantitative analysis of fetal DNA in maternal serum. Hum Genet 2002; 110: 75-9.

11 Rijnders RJ, Van Der Luijt RB, Peters ED et al. Earliest gestational age for fetal sexing in cell-free maternal plasma. Prenat Diagn 2003; 23: 1042-4.

12 Chi C, Hyett JA, Finning KM, Lee CA, Kadir RA. Non-invasive first trimester determination of fetal gender: a new approach for prenatal diagnosis of haemophilia. BJOG 2006; 113: 239-42.

13 Varekamp I, Suurmeijer TP, Brocker-Vriends $\mathrm{AH}$ et al. Carrier testing and prenatal diagnosis for hemophilia: experiences and attitudes of 549 potential and obligate carriers. Am J Med Genet 1990; 37: 147-54.

14 Tedgard U. Carrier testing and prenatal diagnosis of haemophilia - utilisation and psychological consequences. Haemophilia 1998; 4: 365-9.

15 Kadir RA, Sabin CA, Goldman E, Pollard D, Economides DL, Lee CA. Reproductive choices of women in families with haemophilia. Haemophilia 2000; 6: 33-40.

16 Coppola A, Cerbone AM, Mancuso G, Mansueto MF, Mazzini C, Zanon E. Confronting the psychological burden of haemophilia. Haemophilia 2011; 17: 21-7.

17 Plug I, Mauser-Bunschoten EP, BrockerVriends $\mathrm{AH}$ et al. Bleeding in carriers of hemophilia. Blood 2006; 108: 52-6.

18 Sramek A, Eikenboom JC, Briet E, Vandenbroucke JP, Rosendaal FR. Usefulness of patient interview in bleeding disorders. Arch Intern Med 1995; 155: 1409-15.

19 White GC 2nd, Rosendaal F, Aledort LM, Lusher JM, Rothschild C, Ingerslev J. Definitions in hemophilia. Recommendation of the scientific subcommittee on factor VIII and factor IX of the scientific and standardization committee of the International Society on Thrombosis and Haemostasis. Thromb Haemost 2001; 85: 560.

20 Rothman KJ. No adjustments are needed for multiple comparisons. Epidemiology 1990; 1: 43-6.

21 Tedgard U, Ljung R, McNeil TF. Reproductive choices of haemophilia carriers. $\mathrm{Br} J$ Haematol 1999; 106: 421-6.

22 Kadir RA, Economides DL, Braithwaite J, Goldman E, Lee CA. The obstetric experience of carriers of haemophilia. Br J Obstet Gynaecol 1997; 104: 803-10.

23 Chi C, Lee CA, Shiltagh N, Khan A, Pollard D, Kadir RA. Pregnancy in carriers of haemophilia. Haemophilia 2008; 14: 56-64.

24 Santacroce R, Vecchione G, Tomaiyolo M et al. Identification of fetal gender in maternal blood is a helpful tool in the prenatal diagnosis of haemophilia. Haemophilia 2006; 12: 417-22.

25 Bustamante-Aragones A, Rodriguez de Alba M, Gonzalez-Gonzalez C et al. Foetal sex determination in maternal blood from the seventh week of gestation and its role in diagnosing haemophilia in the foetuses of female carriers. Haemophilia 2008; 14: 593-8.

26 Lavery S. Preimplantation genetic diagnosis: new reproductive options for carriers of haemophilia. Haemophilia 2004; 10(Suppl. 4): 126-32.

27 Lavery S. Preimplantation genetic diagnosis of haemophilia. Br J Haematol 2009; 144: 303-7.

28 Wright CF, Chitty LS. Cell-free fetal DNA and RNA in maternal blood: implications for safer antenatal testing. BMJ 2009; 339: b2451. 